\title{
The crossing numbers of products of paths with 7-vertex trees
}

\section{EMÍLIA DRAŽENSKÁ}

\section{ABSTRACT.}

The crossing numbers of Cartesian products of paths with all graphs of order at most five are given. The crossing numbers of Cartesian products of paths with several graphs on six vertices are known. We extend these results by giving the exact values or upper bound of crossing numbers of Cartesian products $G \square P_{n}$ for every tree $G$ on seven vertices.

\section{REFERENCES}

[1] Bokal, D., On the crossing numbers of Cartesian products with paths, J. Combin. theory B, 97 (2007), 381-384

[2] de Klerk, E., Pasechnik, D. V. and Salazar, G., Book drawings of complete bipartite graphs, Discrete Applied Mathematics, 167 (2014), 80-93

[3] Garey, M. R. and Johnson, D. S., Crossing number is NP-complete, SIAM J. Algebraic and Discrete Methods, 4 (1983), 312-316

[4] Jendrol', S. and Ščerbová, M., On the crossing numbers of $S_{m} \times P_{n}$ and $S_{m} \times C_{n}$, Časopis pro pěstování matematiky, 107 (1982), 225-230

[5] Kleitman, D. J., The crossing number of $K_{5, n}, \mathrm{~J}$. Comb. Theory, 9 (1970), 315-323

[6] Klešč, M., On the crossing numbers of Cartesian products of stars and paths or cycles, Mathematica Slovaca, 41 (1991), 113-120

[7] Klešč, M., The crossing numbers of products of 4-vertex graphs with paths and cycles, Discussiones Mathematicae Graph Theory, 19 (1999), 659-669

[8] Klešč, M., The crossing numbers of products of paths and stars with 4-vertex graphs, J. Graph Theory, 18 (1994), 605-614

[9] Klešč, M., The crossing numbers of Cartesian products of paths with 5-vertex graphs, Discrete Math., 233 (2001), 353-359

[10] Klešč, M., The crossing number of $K_{2,3} \times P_{n}$ and $K_{2,3} \times S_{n}$, Tatra Mt. Math. Publ.,9 (1996), 51-56

[11] Kravecová, D., The crossing number of $P_{5}^{2} \times P_{n}$, Creat. Math. Inform., 28 (2012), 49-56

[12] Klešč, M. and Petrillová, J., The crossing numbers of products of path with graphs of order six, Discussiones Mathematicae Graph Theory, 33 (2013), $571-582$

[13] Ouyang, Z., Wang, J. and Huang, Y., The crossing number of the Cartesian product of paths with complete graphs, Discrete Mathematics, 328 (2014), 71-78

TECHNICAL UNIVERSITY

DEPARTMENT OF MATHEMATICS AND THEORETICAL INFORMATiCS

FACULTY OF ELECTRICAL ENGINEERING AND INFORMATICS

LETNÁ 9, 04200 KoŠICE, SLOVAK REPUBLIC

E-mail address: Emilia.Drazenska@tuke.sk 